\title{
EDTAKI: A NEPHROLOGY AND PUBLIC POLICY COMMITTEE (NPPC) PLATFORM CALL FOR MORE EUROPEAN INVOLVEMENT IN AKI
}

\author{
Raymond Vanholder ${ }^{1}$, Eric Rondeau ${ }^{2}$, Hans-Joachim Anders ${ }^{3}$, Nicholas Carlson ${ }^{4}$, \\ Danilo Fliser ${ }^{5}$, Mehmet Kanbay ${ }^{6}$, José António Lopes ${ }^{7}$, Patrick T. Murray ${ }^{8}$, \\ Alberto Ortiz ${ }^{9}$, Ana B. Sanz ${ }^{9}$, Nicholas M. Selby ${ }^{10}$, Andrzej Wiecek ${ }^{11}$, Ziad A. \\ Massy $^{12}$
}

1: Nephrology Section, Department of Internal Medicine and Pediatrics, Ghent University Hospital, Ghent, Belgium; European Kidney Health Alliance (EKHA), Brussels, Belgium

2: Renal Intensive Care and Transplantation Unit, Hôpital TENON, APHP, Paris; Sorbonne Université, Paris, France

3: Division of Nephrology, Department of Medicine IV, University Hospital LMU Munich, Munich, Germany

4: Department of Nephrology, Copenhagen University Hospital Rigshospitalet, Denmark, and Department of Research, The Danish Heart Foundation

5: Internal Medicine IV, Saarland University Medical Center, Homburg/Saar, Germany

6: Nephrology Section, Department of Internal Medicine, Koc University School of Medicine, Istanbul, Turkey

7: Division of Nephrology and Renal Transplantation, Centro Hospitalar Universitário Lisboa Norte, Av. Prof. Egas Moniz, 1649-035, Lisboa, Portugal

8: School of Medicine, University College Dublin, UCD Catherine McAuley Education \& Research Centre, Eccles Street, Dublin 7, Ireland

9: Research Institute Fundacion Jemenez Diaz, Autonoma University Madrid, Spain

10: Centre for Kidney Research and Innovation, Division of Health Sciences and Graduate Entry Medicine, University of Nottingham, UK

11: Department of Nephrology, Transplantation and Internal Medicine, Medical University of Silesia in Katowice, Poland

12: Department of Nephrology, Ambroise Paré University Hospital, APHP, Boulogne-Billancourt/Paris, and Centre for Research in Epidemiology and Population Health (CESP), Paris-Saclay University, Versailles Saint Quentin University, INSERM UMRS 1018, Team5 Villejuif, France

Correspondence to: Raymond Vanholder; Email: Raymond.vanholder@ugent.be

Twitter handles: @EKHA_EU and @ERAEDTA

(C) The Author(s) 2021. Published by Oxford University Press on behalf of ERA-EDTA. All rights reserved. 


\section{ABSTRACT}

Acute Kidney Injury (AKI) is an often neglected but crucial element of clinical nephrology. The aim of the Nephrology Public Policy Committee (NPPC) of the European Renal Association - European Dialysis and Transplant Association (ERA-EDTA) is to promote several key aspects of European nephrology. One of the targets proposed by NPPC was to advance European nephrology involvement in AKI. We undertook literature analyses to define the current position of European nephrology in the field of AKI compared to other regions, and about how different European countries compare to each other. It appeared that vis-à-vis countries with a comparable socio-economic status (the US, Australia, New Zealand, Canada), the European contribution was almost 50\% lower. Within Europe, Central/Eastern Europe and countries with a lower gross domestic product (GDP) showed lower scientific output. Nephrologists contributed to less than half of the output. There was no trend for a change over the last decade. It is concluded that there is room to improve the contribution of European nephrology in the field of AKI. We propose a model on how to promote clinical collaboration on AKI across Europe, the creation of a pan-European nephrology network of interested units is proposed, to improve clinical outcomes, increase nephrologist involvement and awareness outside nephrology, and stimulate research on AKI in Europe. Accordingly, we also propose a list of research priorities and stress the need for more European funding of AKI research.

Keywords: acute kidney injury, AKI, Nephrology and Public Policy Committee, networking, NPPC 


\section{KEY LEARNING POINTS}

\section{What is already known about this subject?}

- Acute Kidney Injury (AKI) is an important kidney problem with high mortality which often receives insufficient attention.

- $\quad$ AKI is one of the key issues proposed for promotion by the Nephrology and Public Policy Committee of ERA-EDTA.

- The contribution of European nephrology to AKI expertise remains unclear.

\section{What this study adds?}

- The European contribution to AKI publications is low compared to other regions with similar wealth.

- Between European countries, there is an East-West gradient but also a low/high income gradient.

- There is no trend for a change over time.

- Nephrologists contributed to less than half of the publications.

What impact this may have on practice or policy?

- This is a wake-up call for European nephrology to join efforts combating AKI.

- We propose a pan-European network of interested units participating in multicentric registration and research.

- We recommend a model with variable involvement depending on the interest.

- We also include a list of research priorities. 


\section{INTRODUCTION}

Until the beginning of this century, at least 30 definitions of Acute Kidney Injury (AKI) were in use $\mathrm{e}^{1,2}$. The introduction of classification systems, although not perfect, resulted in a more systematic approach, acknowledging that already minor changes in kidney function are related to worse outcomes ${ }^{3}$. Nevertheless, AKI is not one disease but an amalgamate concerning many specialties, with a broad spectrum of causes, such as hypovolemia, hypoperfusion, nephrotoxicity, haem-pigments, intravascular coagulation, inflammation, post-renal obstruction ${ }^{4}$, and conditions where several factors coincide, like sepsis ${ }^{5,6}$. The two most involved specialties are nephrology and intensive care medicine ${ }^{7}$. The nephrologist's role, although considered essential ${ }^{8}$, may vary depending on the local situation.

Traditionally Chronic Kidney Disease (CKD) and AKI were viewed as separate entities, but recent knowledge considers the two conditions as intertwined ${ }^{9}$. If the acute condition evolves into CKD and long-term kidney replacement therapy (KRT), this heavily weighs on prognosis, and even more so in countries with limited resources.

The risk of AKI is increased by the presence of comorbidities, including diabetes mellitus, congestive heart failure, arterial hypertension, cardio-vascular disease, chronic obstructive pulmonary disease, secondary immune deficient states like HIV, chronic liver disease, cancer and $C K D^{10,11}$. Not coincidentally, the noncommunicable (chronic) diseases (NCDs) in this list are also linked to CKD development ${ }^{12}$. The increasing survival with most of these comorbidities also widens the time window over which patients are susceptible to $\mathrm{AKI}^{13}$. Also the progressively growing fraction of elderly people ${ }^{14}$ is at increased risk of AKI and of needing KRT in case of AKI ${ }^{15}$.

Epidemiology and phenotype of AKI patients differ between high income countries (HIC) and low-to-middle income countries (LMIC) ${ }^{4,10,16}$, which also applies to Europe as European countries belong to both categories ${ }^{17}$. Global warming may promote further shifts in epidemiology especially in Southern Europe by increasing the risk of dehydration and infectious diseases such as malaria and dengue ${ }^{18,19}$. 


\section{Current status}

The burden of AKI is immense due to its immediate consequences as well as to the increased risk of long-term problems like cardiovascular events in survivors ${ }^{20}$. Even mild AKI is associated with a reduction in survival which remains present even if kidney function recovers ${ }^{21}$. These problems are associated with a health-economic and societal burden, owing to severity of disease, the multiple comorbidities and complications, the need for highly technological interventions (dialysis, artificial ventilation, close monitoring, hemodynamic support, major surgery, etc.), and lengthy recovery periods ${ }^{22,23}$. They also raise ethical questions, on who to treat and who not ${ }^{24}$.

The recent global increase in awareness and action with regards to AKI can to a substantial extent be attributed to the International Society of Nephrology (ISN) which launched in 2015 the ambitious 0by25 initiative (0 preventable deaths due to AKI worldwide by 2025$)^{25}$. Although this action mainly aimed at improving the situation in LMIC, it regards HIC as well, and AKI was recently identified as an important target for the Western European Nephrology community ${ }^{26}$.

In the context of its key role in clinical nephrology and research, the European Renal Association - European Dialysis and Transplant Association (ERA-EDTA) convened several stakeholders in the Nephrology and Public Policy Committee (NPPC) to consider future avenues advancing European clinical kidney research. NPPC defined eight topics to stimulate research collaboration and grant applications in Europe, and decided to translate this plan into public policy action ${ }^{27}$. One of the selected topics was to "extend understanding of AKI progression and complications". The question arising in this context is where Europe and European academia are positioned in the fight against AKI and its consequences. Some may perceive that Europe is lagging behind, but objective pan-European data on this assumption are lacking.

To answer this question, we reviewed the available literature to assess European involvement in AKI compared to other regions worldwide and especially compared to countries with a similar economic or scientific stature, such as the US, Australia-New Zealand or Canada. Based on these data we propose a model on how to promote clinical collaboration and nephrology networking on AKI across Europe. 


\section{Literature analyses - methods}

We first undertook an Endnote search for the entire year 2018 with key terms "acute kidney injury" or "acute renal failure" in the title (referred to by the aggregated term "AKI" in what follows). As this analysis was started in 2019, the year 2018 was selected, as it was the most recent year with complete literature data. Experimental and clinical studies and case reports were included. We excluded publications that were not directly on AKI (e.g. papers on acute graft rejection), and letters and comments. Papers were not excluded based on language or quality criteria. We recorded the nationality of the first author as representative for the origin of the publications.

We first performed an analysis of the absolute number of publications on AKI per region, either a continent, part of a continent (Latin-America, Australia-New Zealand), a group of countries (the non-European Mediterranean countries), or an individual country (US, Canada). We then normalized these data per million population (pmp) which we used as a surrogate for the human resource capacity to perform scientific and/or clinical analyses. The non-European Mediterranean countries were considered as a separate geographic entity because their physicians and researchers are eligible for ERA-EDTA membership.

One of the major questions was the relative scientific output of Europe vs. the US, the other large Western entity with vested research interests. To exclude the possibility of a general trend for a different European kidney research endeavour vs. the US, we performed a similar scientific output analysis with as search terms "chronic kidney disease" and on two more restricted nephrology topics where specific European networks are active: "uremic toxins" (EUTOx) and "hemolytic uremic syndrome" (ERKNet). The ratio of the number of publications for Europe vs. the US for AKI was compared to that for the three other topics. We also calculated the mean impact factor of the journals in which the analysed publications had appeared.

We then ranked all European countries (except those with $<100,000$ inhabitants) for the number of generated AKI publications pmp. We also performed subanalyses comparing Western and Central/Eastern Europe and the highest, middle and lowest tertiles of countries classified based on their GDP pmp. Central/Eastern Europe was defined as the geographic area that formerly was under communist political influence (former Soviet Union, Warsaw 
Pact countries and Yugoslavia, and Albania) plus Turkey. GDP was expressed in US Dollars as provided by Worldometer ${ }^{28}$.

The above comprehensive one year analysis did not permit assessment of the evolution over time. To answer this question, in a second, more restricted, investigation, we assessed the number of publications with the acronym "AKI" in the title (referred to as" AKI in title" in what follows) for the years 2012-2019 and compared the percent share of European contributions to the rest of the world. This examination was also used to assess the contribution of nephrologists vis-à-vis other specialties in Europe and per country. Here also, assessments were based on the nationality of the first author. To analyse specialty involvement, only countries with more than four contributions in the database were included.

\section{RESULTS}

The first large scale analysis for the year 2018 comprised 1554 references. When analysing the publication rate in absolute numbers, Asia had the highest production (564 publications), followed by Europe (438) and the US (362) (table 1 and supplemental figure 1). When publication rate was normalized per million population, the list is headed by Australia-New Zealand and the US (both 1.1 publications pmp) and Canada (1.01). The rate for Europe was almost 50\% lower ( $0.59 \mathrm{pmp}$ ) than that of the US (table 1 and supplemental figure 1 ).

These differences could however also be an illustration of a general trend for lower European activity in scientific and clinical nephrology reporting. We therefore also compared European activity to that of the US for uremic toxicity, the hemolytic uremic syndrome and CKD. The ratio of European over US production was higher for these three topics than for AKI (figure 1). The mean journal impact factors for the European and US AKI papers was the same $(4.2 \pm 7.3$ and $4.3 \pm 7.7)$.

Analysis of scientific output per European country normalized pmp showed substantial differences, from $2.5 \mathrm{pmp}$ (Iceland) to $0.05 \mathrm{pmp}$ (Ukraine and the Russian Federation) (table 2), while twelve of the 43 countries (27.9\%) produced no publications. Of note, the scientific output list is headed by two countries with a population $\leq 500,000$, so that even one single publication gave high scores. When countries were stratified according to a scientific output of $>1.00 \mathrm{pmp}, 0.51-1.00 \mathrm{pmp}, 0.01-0.50 \mathrm{pmp}$ and $0 \mathrm{pmp}$, a definite East/West gradient was 
observed, with a lower scientific output in Central/Eastern Europe (figure 2, table 3). This dichotomy, however, was paralleled by marked differences in country wealth. GDP pmp was almost 5 times higher in Western than in Central/Eastern Europe (table 3). Stratification of European countries in tertiles depending on GDP pmp showed a gradient in proportion to GDP (table 3). However, there are exceptions to this trend, essentially corresponding to smaller countries (Slovenia in the middle GDP tertile with a publication rate of $1.43 \mathrm{pmp}$, and Croatia in the upper part of the lower GDP tertile with 0.98).

The longitudinal analysis based on the inclusion of the acronym AKI in the publication title (2012-2019) included 213 publications. It showed an unmodified share of European contributions vs. the rest of the world in the range of $20-30 \%$ over the entire period under consideration (figure 3, supplemental table 1). All data taken together, the share of nephrologists as first author was slightly less than $50 \%$ whereas other specialists, mainly intensive care physicians, contributed to the remaining half (figure 4). Considering individual countries with 4 publications or more, there were marked differences in contributions from nephrologists, ranging from the majority of contributions by nephrologists (Germany, Spain, Italy) to only a minority (the Netherlands, France) (supplemental table 2).

\section{DISCUSSION}

This study analysed the European contribution to both basic and clinical AKI research as compared to other regions, and made an internal comparison within Europe. The principal findings are:

1) Normalized to pmp inhabitants, the European contribution to AKI research is substantially smaller than that of regions with a similar socio-economic status, such as North-America or ANZA.

2) The discrepancy vs. the US was not observed for other nephrology research topics, such as the Hemolytic Uremic Syndrome, uremic toxicity or CKD. These differences are not paralleled by the mean of the impact factors of the journals in which the papers appeared.

3) A manifest East-West gradient in scientific output exists and this trend parallels disparities in country wealth. 
4) The contribution of nephrology to European AKI publications is less than $50 \%$, with intensive care medicine as an almost equivalent contributing specialty.

5) There is no signal of change in European activity over the past decade.

The relatively low contribution of European nephrology to AKI research is worrisome in view of the clinical and health-economic burden of $\mathrm{AKI}^{20}$. In addition, contributing factors to the incidence of this condition will very likely gain in importance in future due to the population aging ${ }^{24}$ and improved outcomes of other associated conditions such as cardio-vascular disease $\mathrm{e}^{29,30}$ or cancer $^{31}$. Also related costs are projected to increase ${ }^{22}$. Hence, research in this field is essential for the medical community, patients and society alike. It would be unfavourable for Europe not to be in the frontline of unravelling the patho-physiology and searching for new cures for AKI, as a backlog in progress would force European nephrology to largely depend on non-European data and therapeutic solutions.

Some may argue that the scanty European contribution in AKI is emblematic for a global lack of European interest in kidney research. However, this assumption is not mirrored for other nephrology topics and especially not for areas where European networks like EUTox or ERKNET are active (figure 1). Likewise, one may argue that if the analysis would have been limited to Western Europe, scientific output would have been closer to that from the US, Canada, or Australia-New Zealand. However, it would be unlikely for scientific output in those countries to be geographically more homogeneous than it is in Europe. In addition, for policy action and improvement initiatives, it is preferable to consider the European Union and Europe as one entity. Finally, even if the first author is not European, Europeans might be further ranked co-authors. However, we thought that the first author is in most cases the most important contributor to a publication, reflecting the place where the analysis, observation or study took place, while they in addition most often are junior staff members, who constitute the future of medical interest in a given topic, in this case AKI.

The essential role of the nephrologist in AKI has repeatedly been emphasized ${ }^{9,32,33}$. First of all, not all AKI cases are in need of critical care and in those patients the nephrologists may be crucial to timely identify the problem and its causes and for instructing therapy, as well as play an educational role and raise awareness among non-nephrologists and non-AKI physicians. Also in ICU patients, the causes may not be the more usual critical conditions like 
sepsis or kidney hypoperfusion, but intrinsic kidney disorders for which nephrologists can be instrumental in diagnosis and management. In addition, nephrologists can advise on correction of electrolyte disorders ${ }^{32}$, and interpretation of serum creatinine ${ }^{34}$. Second, nephrologists master a broad spectrum of kidney replacement therapies, including intermittent and extended hemodialysis and peritoneal dialysis ${ }^{35}$, which may help adapt to overwhelmed healthcare systems like during the ongoing COVID-19 pandemic ${ }^{36}$. Third, nephrologists may assist in avoiding futile therapy, e.g. in frail AKI patients ${ }^{24,32,37}$. Fourth, and above all, in view of the frequent link with CKD, the nephrologist can play a role in preventing evolution towards CKD and to steer the approach and follow-up if kidney function does not recover $9,38,39$. Thus, we call not only for European research activity on AKI, but also for clinical involvement of the nephrologist in AKI outside the nephrology unit. Unfortunately, if the publication activity as illustrated in this study is also representative of the clinical involvement of nephrologists, our data suggests ample room for increasing this participation. Vice versa, more commitment will increase visibility of nephrology in the area of AKI. As the relation with other specialties might differ between countries and hospitals, mapping of the current situation might be of interest.

The representation of ICU-specialists in AKI literature does not reflect the actual epidemiology of AKI in hospitals and is likely biasing understanding of AKI. In a recent European study from a single tertiary hospital, based on an electronic screening of patient records using KDIGO criteria, ICU cases accounted for only $3 \%$ of hospital-acquired $A K I^{40}$. Of note, this analysis is based on a single centre and the situation might differ in settings with different healthcare systems or patient mix. In addition, the study contained but was by definition not limited to ICU patients, but in this way exactly stresses that AKI is frequent also outside the ICU.

The recent COVID-19 pandemic illustrates several of the concerns raised above. The frequent presence of cytokine storm suggested a high propensity for $A \mathrm{KI}^{41}$, and the many negative facets of AKI, such as the high complication rate, mortality and technical demands, emerged in a timewise condensed way, while AKI appeared to be a major complication in many of the most severely affected COVID-19 patients ${ }^{42-45}$. However, especially in the early phase of the pandemic, European nephrology needed to rely on epidemiologic data from China ${ }^{46}$ or the US ${ }^{47}$, although the first cases in Europe and the US were reported almost 
simultaneously ${ }^{48,49}$. The ERA-EDTA took the laudable decision to open a registry on COVID19 and its links to kidney disease (ERACODA) ${ }^{50,51}$, but to the best of our knowledge this database remained limited to dialysis patients and transplant recipients.

To improve this situation and boost the European contribution to AKI, we propose the development of a European nephrology network of clinicians and researchers with interest in AKI. For each country one or more coordinators are invited to convene interested groups in their regional/national environment. Networks are among the tools to advance interest, knowledge and outcomes of $\mathrm{AKI}^{52}$ and exist already in some European countries like the UK ${ }^{53}$ and France ${ }^{54}$ but should be rolled out at a broad European level, e.g. by applying for a European Cooperation in Science and Technology (COST) action. Once installed, participants will be offered the opportunity to contribute to European registration and research projects and proposals for EU support via Framework Programs like Horizon Europe ${ }^{55}$. Some initiatives may be global and include a broad array of participants; others may be restricted to a few interested parties, applying a model similar to that of the European Uremic Toxin Work Group EUTox ${ }^{56,57}$. The network could also be instrumental in developing pan-European projects to improve clinical outcomes, such as developing a uniform laboratory AKI alert system, preferably inspired upon existing systems ${ }^{58}$. Networking may however not be the only solution. An additional focus point could be the extension of involvement of the nephrologist in AKI outside nephrology (intensive care but also other specialties like oncology, cardiology, surgery etc). However, a European network could also play a crucial coordinating role in promoting and organizing this evolution.

The group should define its immediate and long-term research priorities. A preliminary, nonexhaustive list of such topics can be found in table 4 .

The lower participation in Central/Eastern Europe should not be considered as a symptom of lack of interest or quality care, but the parallelism with GDP is striking. We can only speculate on the reasons but a probable role can be attributed to lower resources for research, lack of time for physicians possibly resulting in less attention to AKI cases, or, since the number of nephrologists is lower in Central/Eastern than in Western Europe ${ }^{59}$, lower specialist numbers. We plead for active involvement of Central/Eastern Europe, especially since differences in epidemiology may lead to interesting observations and a broader pathophysiologic diversity. 
Our analysis has a number of drawbacks. The first, most extended, analysis, covered only one year. Countries might have reached a different profile in another year. It is however unlikely that this would have affected the general comparisons between regions or countries. Second, a number of references may have been missed if the title was not containing the pre-defined keywords, but again, this would unlikely affect general trends. Third, the use of the address of the first author, may not always be representative to define the country where the study was executed. Fourth, the long-term analysis with comparisons between specialties was based on a second, smaller database, which might have been biased by the lower number of retrieved papers, while the term AKI in the title might have been used to a different degree dependent on the year, specialty or country of origin. Finally, the lower publication rate in Central/Eastern Europe might be attributable to a number of publications in local language, which may have been missed in our search.

On the other hand, our analysis also has a number of strengths. To our knowledge, this is the first analysis of scientific output on AKI research of the European nephrology community with comparisons of different aspects, such as regional and country activity, evolution over time and involved specialties, and impact of country wealth. In addition, it was broad enough to give useful indications on how to inform future initiatives to modify the situation. In conclusion, this analysis shows, compared to countries or regions with comparable socioeconomic stature, a relative lack of European initiatives to study and to report on clinical observations with regards to AKI. As for other focus areas defined by NPPC, Central/Eastern European and low income countries appear to demand special consideration ${ }^{60}$. The data also underscore that the involvement of the nephrologists in this domain could be improved. The fact that only one author of this paper is a woman suggests that there is also room for more involvement of women. More time could be devoted to AKI in European nephrology conferences (in the recent ERA-EDTA meetings markedly more slots were devoted to CKD than to $\mathrm{AKI}$ ) and in continuing medical education courses (CMEs), especially in LMIC. Furthermore, increased focus on AKI in European research programs with more funding for AKI studies is another necessity. To cope with these problems, a European nephrology network of researchers and clinicians interested in AKI will be created under the auspices of ERA-EDTA, with the intent to instigate interest in AKI and to develop common research projects. 


\section{CONFLICT OF INTEREST STATEMENT}

HJ Anders reports personal fees from Secarna; grants and personal fees from Previpharma; personal fees from Novartis, Bayer, GSK, Boehringer and AstraZeneca, outside the submitted work.

PT Murray reports personal fees from AM-Pharma, FAST Biomedical and Renibus Therapeutics, outside the submitted work.

A Ortiz reports grants from Servier, Sanofi, and Mundipharma; personal fees from Sanofi, Amgen, AstraZeneca, Otsuka, and Kyowa, outside the submitted work.

E Rondeau reports grants, personal fees and non-financial support from Alexion Pharmaceuticals, outside the submitted work.

None of the remaining authors declared a conflict of interest.

\section{DATA AVAILABILITY STATEMENT}

The data underlying this article are available in the article and in its online supplementary material. 
Table 1. Publications on AKI per region in 2018

\begin{tabular}{|l|c|c|c|c|c|}
\hline & $\begin{array}{c}\text { Absolute N } \\
\text { of } \\
\text { publications }\end{array}$ & $\begin{array}{c}\text { Share of } \\
\text { total } \\
\text { publications } \\
\text { (\%) }\end{array}$ & $\begin{array}{c}\text { population } \\
\text { in millions }\end{array}$ & $\begin{array}{c}\text { publications } \\
\text { pmp* }\end{array}$ & $\begin{array}{c}\text { Share of } \\
\text { total } \\
\text { publications } \\
\text { pmp (\%) }\end{array}$ \\
\hline Africa** & 16 & 1.0 & $1,216.0$ & 0.01 & 0.1 \\
\hline ANZ & 33 & 2.1 & 29.9 & 1.10 & 24.9 \\
\hline Asia & 564 & 36.3 & $4,463.0$ & 0.35 & 7.9 \\
\hline Canada & 38 & 2.4 & 37.6 & 1.01 & 22.8 \\
\hline Europe & 438 & 28.1 & 741.4 & 0.59 & 13.3 \\
\hline Latin-America & 69 & 4.4 & 626.0 & 0.11 & 2.5 \\
\hline Mediterranean & 63 & 2.2 & $227.5 * * *$ & 0.15 & 3.4 \\
\hline US & 362 & 23.3 & 328.2 & 1.10 & 24.9 \\
\hline
\end{tabular}

N: number; pmp: per million population; US: United States; ANZ: Australia-New Zealand ${ }^{*}$ : ratio $=$ number per million population; ${ }^{* *}$ : sub-Saharan Africa; ${ }^{* *}$ : total population of Syria, Lebanon, Israel, Egypt, Libya, Algeria, Tunisia, Morocco. 
Table 2. European publication rate on AKI in $\mathbf{2 0 1 8}$ per country normalized pmp

\begin{tabular}{|l|c|c|c|}
\hline Country & N of publications & Population (millions) & N of publications pmp \\
\hline Iceland & 1 & 0.4 & 2.50 \\
\hline Malta & 1 & 0.5 & 2.00 \\
\hline Switzerland & 13 & 8.5 & 1.53 \\
\hline Slovenia & 3 & 2.1 & 1.43 \\
\hline Denmark & 8 & 5.8 & 1.38 \\
\hline The Netherlands & 23 & 17.4 & 1.32 \\
\hline Belgium & 15 & 11.4 & 1.32 \\
\hline Finland & 6 & 5.5 & 1.09 \\
\hline Portugal & 11 & 10.3 & 1.07 \\
\hline Italy & 63 & 60.4 & 1.04 \\
\hline Croatia & 4 & 4.1 & 0.98 \\
\hline Austria & 8 & 8.9 & 0.90 \\
\hline United Kingdom & 59 & 66.4 & 0.89 \\
\hline Cyprus & 1 & 1.2 & 0.83 \\
\hline Sweden & 8 & 10.1 & 0.79 \\
\hline Greece & 8 & 10.3 & 0.78 \\
\hline Spain & 34 & 46.7 & 0.73 \\
\hline Germany & 60 & 82.9 & 0.72 \\
\hline France & 45 & 67.1 & 0.67 \\
\hline Ireland & 3 & 4.9 & 0.61 \\
\hline North-Macedonia & 1 & 2.1 & 0.48 \\
\hline Poland & 15 & 38.4 & 0.39 \\
\hline Norway & 2 & 5.3 & 0.38 \\
\hline Slovak Republic & 2 & 5.4 & 0.37 \\
\hline Lithuania & 1 & 2.8 & 0.36 \\
\hline Turkey & 29 & 83.1 & 0.35 \\
\hline Georgia & 3.7 & 0.27 \\
\hline Romania & 1 & 19.5 & 0.15 \\
\hline Serbia & 3.0 & 0.14 \\
\hline Russian Federation & 145.9 & 0.05 \\
\hline Ukraine & 41.7 & 0.05 \\
\hline & & & \\
\hline
\end{tabular}

$\mathrm{N}$ : number; pmp: per million people. Small countries (less than 100,000 inhabitants) like Andorra, Liechtenstein, Monaco, San Marino, Vatican, were not included. No publications for: Albania, Belarus, Bosnia-Herzegovina, Bulgaria, Czech Republic, Estonia, Hungary, Kosovo, Latvia, Luxembourg, Moldova, Montenegro. 
Table 3. Relation between scientific output (publications on the topic of AKI in 2018), and geographic location and GDP

\begin{tabular}{|c|c|c|c|c|c|}
\hline Region & $\begin{array}{l}\text { West/East } \\
\text { (number of } \\
\text { countries) }\end{array}$ & $\begin{array}{l}\text { GDP pmp (US } \\
\text { dollars) } \\
\text { mean } \pm S D \text { ) }\end{array}$ & $\begin{array}{l}\text { GDP pmp (US } \\
\text { dollars) [median } \\
\text { (range)] }\end{array}$ & $\begin{array}{l}\text { Scientific } \\
\text { output } \\
\text { (mean } \pm S D \text { ) }\end{array}$ & $\begin{array}{l}\text { Scientific } \\
\text { output } \\
\text { [median } \\
\text { (range)] }\end{array}$ \\
\hline Western Europe & $20 / 0$ & $48640 \pm 22256$ & $\begin{array}{l}42229 \\
(105280-18695)\end{array}$ & $1.03 \pm 0.54$ & $0.90(2.50-0)$ \\
\hline $\begin{array}{l}\text { Central/Eastern } \\
\text { Europe }\end{array}$ & $0 / 21$ & 9877士6119* & $\begin{array}{l}9198 \\
(23488-2002)\end{array}$ & $0.20 \pm 0.36 * *$ & $0(1.43-0)$ \\
\hline \multicolumn{6}{|l|}{ GDP pmp } \\
\hline Highest tertile & $14 / 0$ & $58513 \pm 18561$ & $\begin{array}{l}51436 \\
(105280-39532)\end{array}$ & $1.01 \pm 0.58$ & $0.9(2.50-0)$ \\
\hline Middle tertile & $6 / 8$ & $20720 \pm 5345$ & $\begin{array}{l}19692 \\
(32038-13871)\end{array}$ & $0.64 \pm 0.58$ & $0.65(2.00-0)$ \\
\hline Lowest tertile & $0 / 15$ & $6641 \pm 3273$ & $\begin{array}{l}5418 \\
(13200-2002)\end{array}$ & $0.16 \pm 0.26 * * *$ & $0.05(0.98-0)$ \\
\hline
\end{tabular}

Scientific output was calculated as number of publications pmp. GDP: gross domestic product. Pmp: per million population.

*: $p<0.001$ vs. West; ${ }^{* *}: p<0.01$ vs. West; ${ }^{* * *}: p<0.01$ vs. highest tertile. 
Table 4. Research priorities

\begin{tabular}{|l|}
\hline IMMEDIATE \\
\hline Develop a uniform transnational European alarm system and assess clinical impact \\
\hline $\begin{array}{l}\text { Prospective registry with follow-up at 1, 3, } 6 \text { months with epidemiology and outcomes } \\
\text { (albuminuria, eGFR, complications, death, dialysis) in different countries - possibly } \\
\text { coupled to proteomic/genomic biobank }\end{array}$ \\
\hline Impact of cessation or not of RAAS-inhibitors on evolution of AKI \\
\hline Mechanisms of AKI in cancer patients \\
\hline $\begin{array}{l}\text { Observational study of the different models of AKI care across European healthcare } \\
\text { systems i.e. 'practice patterns' type of approach }\end{array}$ \\
\hline $\begin{array}{l}\text { Develop tools that reliably assess the I in AKI, as opposed to current tools that evaluate } \\
\text { function }\end{array}$ \\
\hline $\begin{array}{l}\text { A systems biology approach to AKI diagnosis and categorization enabling evaluation of } \\
\text { different therapeutic approaches in uniform buckets of cases }\end{array}$ \\
\hline Create a European network of clinical trialists \\
\hline Explore novel imaging techniques for the diagnosis of AKI \\
\hline Assess epidemiology and risk factors in vulnerable populations (e.g. the elderly) \\
\hline $\begin{array}{l}\text { Describe primary and secondary preventive measures and their impact on AKI } \\
\text { development and severity }\end{array}$ \\
\hline
\end{tabular}

\begin{tabular}{|l|}
\hline LONG-TERM \\
\hline $\begin{array}{l}\text { Prospective registry with follow-up at } \geq 1 \text { year with epidemiology and outcomes } \\
\text { (albuminuria, eGFR, complications, death, dialysis) in different countries - possibly } \\
\text { coupled to proteomic/genomic biobank - extension of the immediate priority above }\end{array}$ \\
\hline Health-economic impact of transition of AKI to CKD \\
\hline $\begin{array}{l}\text { Patho-physiologic studies of target molecules and mechanisms, their receptors and } \\
\text { pathways }\end{array}$ \\
\hline Interventional trials of prevention or treatment of AKI \\
\hline Prognostic impact of uremic toxins in AKI \\
\hline Prognostic impact of outpatient AKI \\
\hline $\begin{array}{l}\text { Monitor the impact of widespread SGLT2 inhibitor uptake on the incidence and outcome } \\
\text { implications of AKI }\end{array}$ \\
\hline $\begin{array}{l}\text { Describe impact of primary and secondary preventive measures on long-term AKI } \\
\text { outcomes }\end{array}$ \\
\hline $\begin{array}{l}\text { Development and evaluation of tools using artificial intelligence to identify patients at } \\
\text { risk for AKI and to predict the severity of AKI outcomes }\end{array}$ \\
\hline
\end{tabular}

RAAS: renin angiotensin aldosterone system; AKI: acute kidney injury; CKD: chronic kidney disease; SGLT: sodium-glucose transport 
Figure 1: Ratio of the number of publications in Europe over the US for acute kidney injury (AKI), Chronic Kidney Disease (CKD), Hemolytic Uremic Syndrome (HUS) and Uremic Toxins (UTox) in 2018.

Figure 2: European publication rate on AKI in 2018 per country normalized pmp. Darkness of shade in proportion to publication rate (darkest for highest rate). Rates were calculated as number of publications on AKI based on AKI in title. Blue colors: publication rate $>1.00 \mathrm{pmp}, 0.51-1.00 \mathrm{pmp}$, 0.01-0.50 pmp. Grey: publication rate 0 . There is a marked East-West gradient.

Figure 3: Year by year European contribution to publications on AKI (\% publications out of overall worldwide publications, based on AKI in title). There was no significant trend.

Figure 4: Percent contribution of different specialties in European publications with AKI in the title (2012-2019). 


\section{REFERENCES}

1. Lameire N, Van Biesen W, Vanholder R. The changing epidemiology of acute renal failure. Nature Clin Pract Nephrol 2006; 2: 364-377.

2. Kellum JA, Levin N, Bouman C, Lameire N. Developing a consensus classification system for acute renal failure. Curr Opin Crit Care 2002; 8: 509-514.

3. Lassnigg A, Schmidlin D, Mouhieddine M, et al. Minimal changes of serum creatinine predict prognosis in patients after cardiothoracic surgery: a prospective cohort study. J Am Soc Nephrol 2004; 15: 1597-1605.

4. Hoste EAJ, Kellum JA, Selby NM, et al. Global epidemiology and outcomes of acute kidney injury. Nature Rev Nephrol 2018; 14: 607-625.

5. Wan L, Bagshaw SM, Langenberg C, Saotome T, May C, Bellomo R. Pathophysiology of septic acute kidney injury: what do we really know? Crit Care Med 2008; 36 (Suppl 4): S198-S203.

6. Vanmassenhove J, Glorieux G, Hoste E, Dhondt A, Vanholder R, Van Biesen W. AKI in early sepsis is a continuum from transient AKI without tubular damage over transient AKI with minor tubular damage to intrinsic AKI with severe tubular damage. Int Urol Nephrol 2014; 46: 2003-2008.

7. Lee SA, Cozzi M, Bush EL, Rabb H. Distant Organ Dysfunction in Acute Kidney Injury: A Review. Am J Kidney Dis 2018; 72: 846-856.

8. Mehboob A, Zimmerman R, Abramson S, Parker MG. Quality measures in acute kidney injury. Curr Opin Nephrol Hypertension 2018; 27: 130-135.

9. Chawla $L S$, Bellomo R, Bihorac $A$, et al. Acute kidney disease and renal recovery: consensus report of the Acute Disease Quality Initiative (ADQI) 16 Workgroup. Nature Rev Nephrol 2017; 13: 241-257.

10. Lameire NH, Bagga A, Cruz D, et al. Acute kidney injury: an increasing global concern. Lancet 2013; 382: 170-179.

11. Kheterpal S, Tremper KK, Heung M, et al. Development and validation of an acute kidney injury risk index for patients undergoing general surgery: results from a national data set.

Anesthesiology 2009; 110: 505-515.

12. Vanholder R, Annemans L, Brown E, et al. Reducing the costs of chronic kidney disease while delivering quality health care: a call to action. Nature Rev Nephrol 2017; 13: 393-409.

13. Lameire N, Vanholder R, Van Biesen W, Benoit D. Acute kidney injury in critically ill cancer patients: an update. Crit Care 2016; 20: 209.

14. Coca SG. Acute kidney injury in elderly persons. Am J Kidney Dis 2010; 56: 122-131.

15. Ishani A, Xue JL, Himmelfarb J, et al. Acute kidney injury increases risk of ESRD among elderly. J Am Soc Nephrol 2009; 20: 223-228.

16. Nash DM, Przech S, Wald R, O'Reilly D. Systematic review and meta-analysis of renal replacement therapy modalities for acute kidney injury in the intensive care unit. J Crit Care 2017; 41: 138-144.

17. https://datahelpdesk.worldbank.org/knowledgebase/articles/906519-world-bank-countryand-lending-groups.

18. Barraclough KA, Blashki GA, Holt SG, Agar JWM. Climate change and kidney disease-threats and opportunities. Kidney Int 2017; 92: 526-530.

19. Chretien JP, Anyamba A, Small J, et al. Global climate anomalies and potential infectious disease risks: 2014-2015. PLoS Curr 2015; 7.

20. Ostermann M, Cerda J. The Burden of Acute Kidney Injury and Related Financial Issues.

Contrib Nephrol 2018; 193: 100-112.

21. Bihorac A, Yavas S, Subbiah S, et al. Long-term risk of mortality and acute kidney injury during hospitalization after major surgery. Ann Surg 2009; 249: 851-858.

22. Silver SA, Long J, Zheng Y, Chertow GM. Cost of Acute Kidney Injury in Hospitalized Patients. J Hosp Med 2017; 12: 70-76. 
23. Kerr M, Bedford M, Matthews B, O'Donoghue D. The economic impact of acute kidney injury in England. Nephrol Dial Transplant 2014; 29: 1362-1368.

24. Akbar S, Moss AH. The ethics of offering dialysis for AKI to the older patient: time to reevaluate? Clin J Am Soc Nephrol 2014; 9: 1652-1656.

25. Mehta RL, Cerda J, Burdmann EA, et al. International Society of Nephrology's Oby25 initiative for acute kidney injury (zero preventable deaths by 2025): a human rights case for nephrology. Lancet 2015; 385: 2616-2643.

26. Rondeau E, Luyckx VA, Anders HJ, et al. Challenges and opportunities for nephrology in Western Europe. Kidney Int 2019; 95: 1037-1040.

27. Massy ZA, Caskey FJ, Finne P, et al. Nephrology and Public Policy Committee propositions to stimulate research collaboration in adults and children in Europe. Nephrol Dial Transplant 2019; 34: 1469-1480.

28. https://www.worldometers.info/gdp/gdp-per-capita/.

29. Vanholder R, Massy Z, Argiles A, et al. Chronic kidney disease as cause of cardiovascular morbidity and mortality. Nephrol Dial Transplant 2005; 20: 1048-1056.

30. Matsushita K, Coresh J, Sang Y, et al. Estimated glomerular filtration rate and albuminuria for prediction of cardiovascular outcomes: a collaborative meta-analysis of individual participant data. Lancet Diabetes Endocrinol 2015; 3: 514-525.

31. Stengel B. Chronic kidney disease and cancer: a troubling connection. J Nephrol 2010; 23: 253-262.

32. Endre ZH. The Role of Nephrologist in the Intensive Care Unit. Blood Purif 2017; 43: 78-81.

33. Chawla LS. The expanding role of the nephrologist in the intensive care unit. Clin J Am SoC Nephrol 2008; 3: 545.

34. Chen S. Retooling the creatinine clearance equation to estimate kinetic GFR when the plasma creatinine is changing acutely. J Am Soc Nephrol 2013; 24: 877-888.

35. Farooq U, Tober A, Chinchilli V, Reeves WB, Ghahramani N. Definition, Management, and Outcomes of Acute Kidney Injury: An International Survey of Nephrologists. Kidney Dis (Basel) 2017; 3: 120-126.

36. Ponce D, Balbi AL, Durand JB, Moretta G, Divino-Filho JC. Acute peritoneal dialysis in the treatment of COVID-19-related acute kidney injury. Clin KidneyJ 2020; 13: 269-273.

37. Martin DE, Harris DCH, Jha V, et al. Ethical challenges in nephrology: a call for action. Nature Rev Nephrol 2020; 16: 603-613.

38. Vanmassenhove J, Vanholder R, Lameire N. Points of Concern in Post Acute Kidney Injury Management. Nephron 2017; 138: 92-103.

39. Harel Z, Wald R, Bargman JM, et al. Nephrologist follow-up improves all-cause mortality of severe acute kidney injury survivors. Kidney Int 2013; 83: 901-908.

40. Martin-Cleary C, Molinero-Casares LM, Ortiz A, Arce-Obieta JM. Development and internal validation of a prediction model for hospital-acquired acute kidney injury. Clin Kidney J 2019; doi: https://doi.org/10.1093/ckj/sfz139.

41. Batlle D, Soler MJ, Sparks MA, et al. Acute Kidney Injury in COVID-19: Emerging Evidence of a Distinct Pathophysiology. J Am Soc Nephrol 2020; 31: 1380-1383.

42. Ronco C, Reis T, Husain-Syed F. Management of acute kidney injury in patients with COVID19. Lancet Respir Med 2020; 8: 738-742.

43. Hirsch JS, Ng JH, Ross DW, et al. Acute kidney injury in patients hospitalized with COVID-19. Kidney Int 2020; 98: 209-218.

44. Pei G, Zhang Z, Peng J, et al. Renal Involvement and Early Prognosis in Patients with COVID-19 Pneumonia. J Am Soc Nephrol 2020; 31: 1157-1165.

45. https://www.nytimes.com/2020/04/18/health/kidney-dialysis-coronavirus.html.

46. Guan WJ, Ni ZY, Hu Y, et al. Clinical Characteristics of Coronavirus Disease 2019 in China. New Eng J Med 2020; 382: 1708-1720. 
47. Richardson S, Hirsch JS, Narasimhan M, et al. Presenting Characteristics, Comorbidities, and Outcomes Among 5700 Patients Hospitalized With COVID-19 in the New York City Area. JAMA 2020; 323: 2052-2059.

48. Spiteri G, Fielding J, Diercke M, et al. First cases of coronavirus disease 2019 (COVID-19) in the WHO European Region, 24 January to 21 February 2020. Euro Surveill 2020; 25 doi:

10.2807/1560-7917.ES.2020.25.

49. Holshue ML, DeBolt C, Lindquist S, et al. First Case of 2019 Novel Coronavirus in the United States. New Eng J Med 2020; 382: 929-936.

50. https://www.era-edta.org/en/covid-19-news-and-information/\#toggle-id-4.

51. Hilbrands LB, Duivenvoorden R, Vart $P$, et al. COVID-19-related mortality in kidney transplant and dialysis patients: results of the ERACODA collaboration. Nephrol Dial Transplant 2020; 35: 19731983.

52. Mehta RL, Kellum JA, Shah SV, et al. Acute Kidney Injury Network: report of an initiative to improve outcomes in acute kidney injury. Crit Care 2007; 11: R31.

53. Selby NM, Casula A, Lamming L, et al. An Organizational-Level Program of Intervention for AKI: A Pragmatic Stepped Wedge Cluster Randomized Trial. J Am Soc Nephrol 2019; 30: 505-515.

54. Rondeau E, Faguer S, Robert T. Advocacy for a European network of renal intensive care units. Nephrol Dial Transplant 2019; 34: 1262-1264.

55. https://ec.europa.eu/info/horizon-europe-next-research-and-innovation-frameworkprogramme_en.

56. https://www.uremic-toxins.org/.

57. Vanholder R, Abou-Deif O, Argiles A, et al. The role of EUTox in uremic toxin research. Semin Dial 2009; 22: 323-328.

58. West Midlands Acute Medicine C. The impact of the NHS electronic-alert system on the recognition and management of acute kidney injury in acute medicine. Clin Med (Lond) 2019; 19: 109-113.

59. Osman MA, Alrukhaimi M, Ashuntantang GE, et al. Global nephrology workforce: gaps and opportunities toward a sustainable kidney care system. Kidney Int Suppl 2018; 8: 52-63.

60. Sever MS, Jager, K, Vanholder, R, Stengel, B, Harambat, J, Finne, P, Tesar, V, Barbullushi, M, Bumblyte, IA, Zakharova, E, Spasovski, G, Resic, H, Wiecek, A, Blankestijn, PJ, Bruchfeld, A, Cozzolino, M, Goumenos, D, Soler, MJ, Rychlik, I, Stevens, K, Wanner, C, Zoccali, C, Massy ZA A roadmap for optimizing chronic kidney disease patient care and patient-oriented research in the Eastern European nephrology community. Clin Kidney J 2021 in press; doi: 10.1093/ckj/sfaa218 


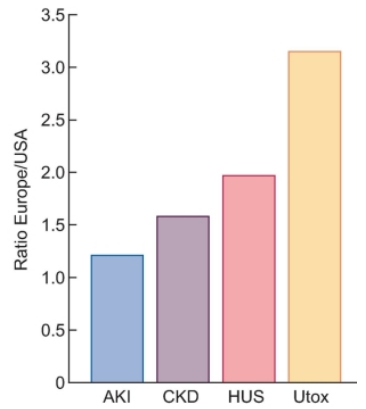

NDT-02044-2020.R1-fig1

$66 \times 253 \mathrm{~mm}(300 \times 300 \mathrm{DPI})$ 


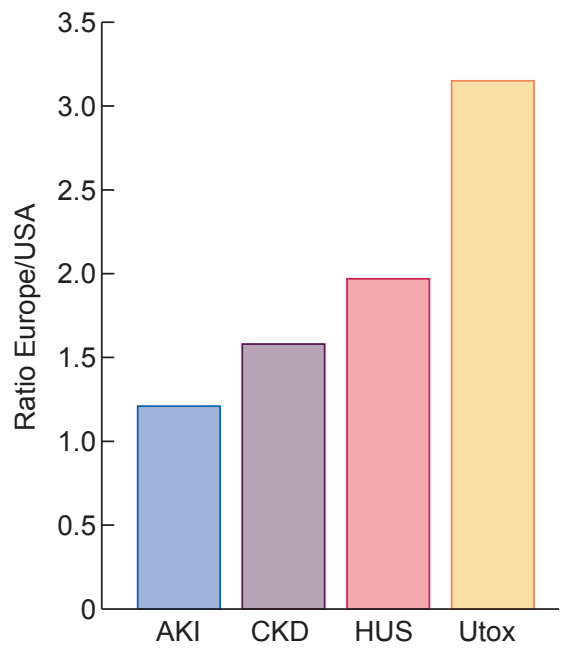




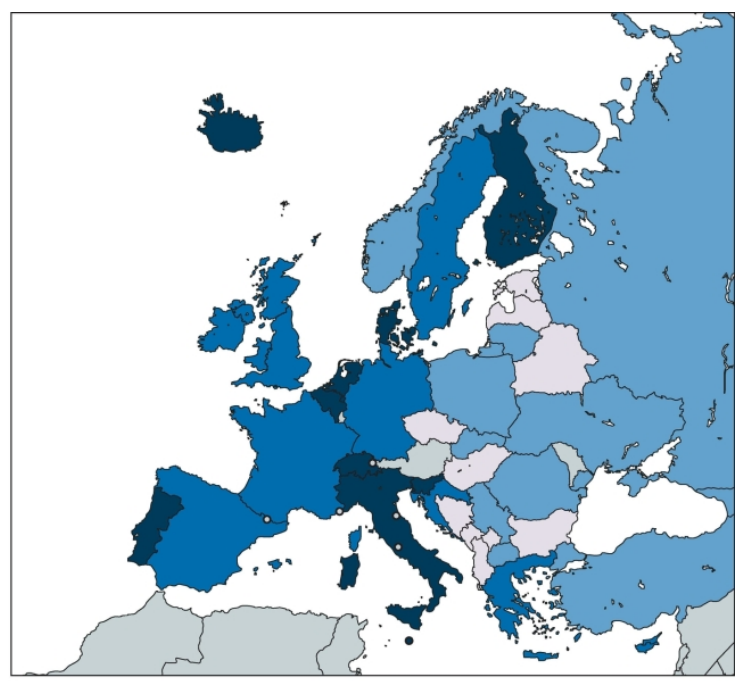

NDT-02044-2020.R1-fig2

$146 \times 254 \mathrm{~mm}(300 \times 300$ DPI $)$ 


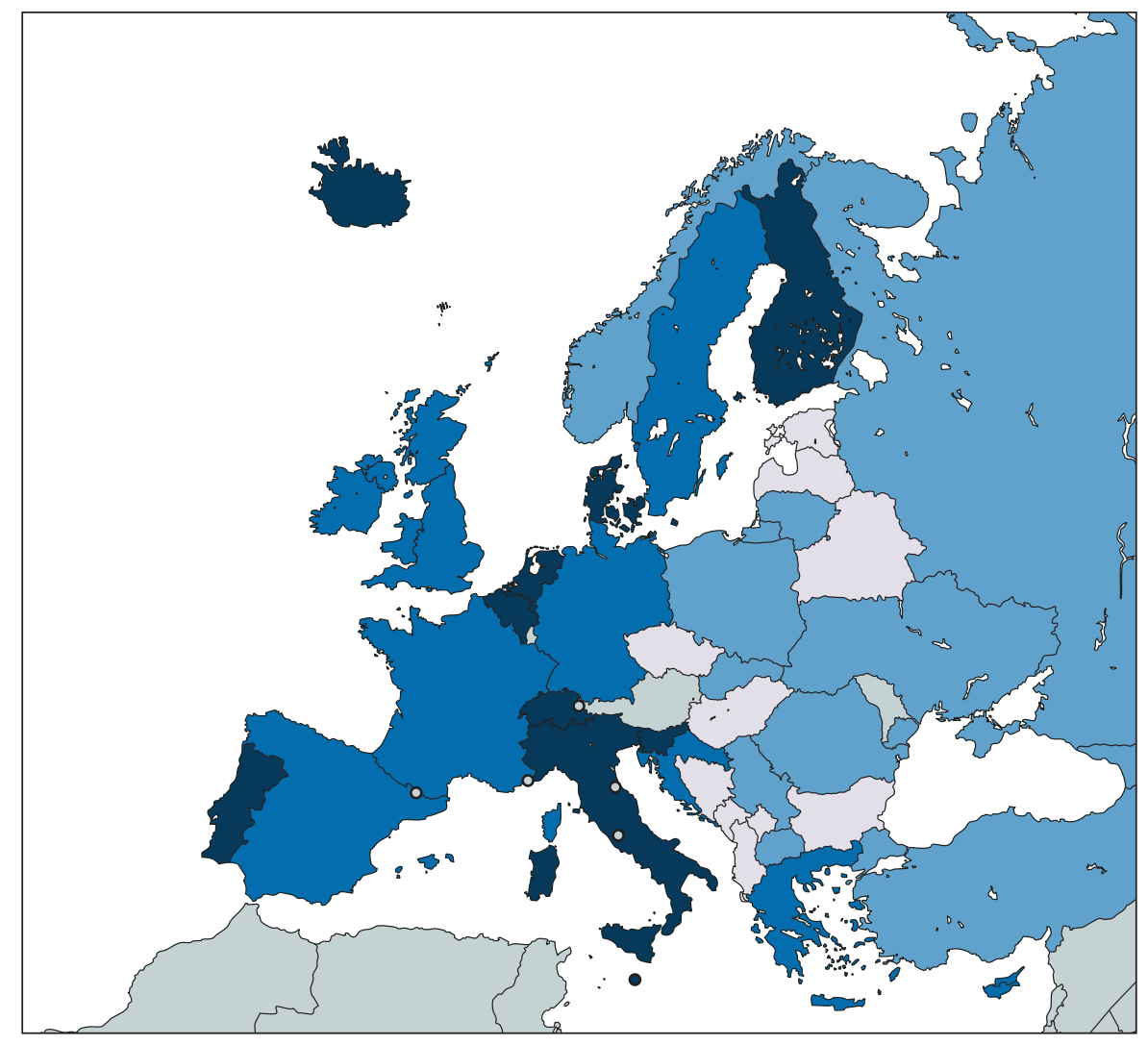




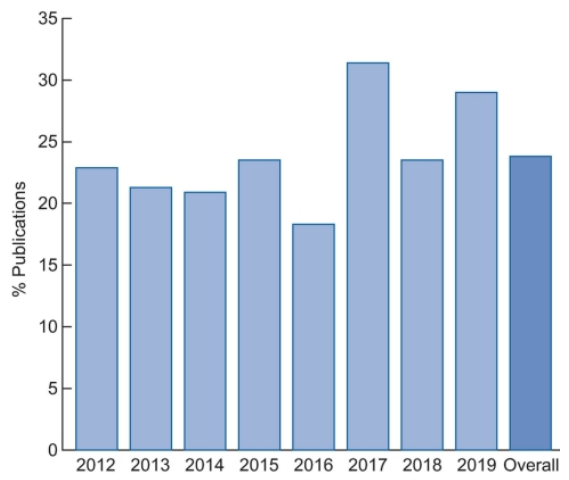

NDT-02044-2020.R1-fig3

$87 \times 248 \mathrm{~mm}(300 \times 300$ DPI $)$ 


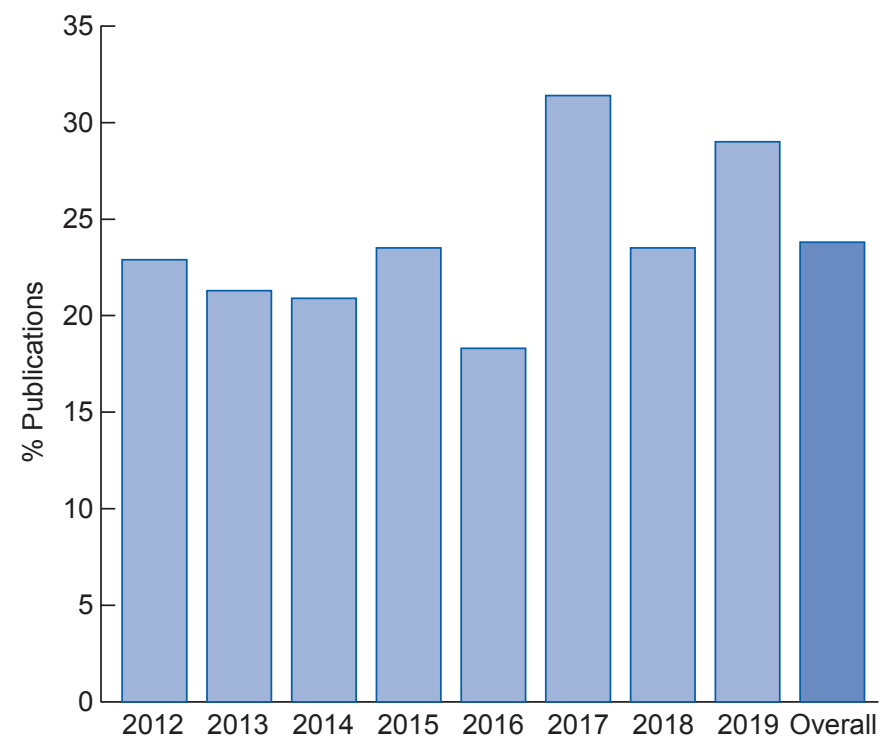




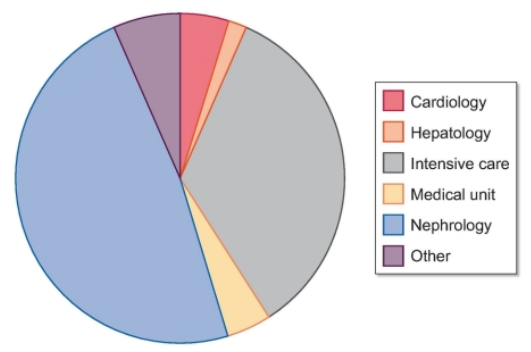

NDT-02044-2020.R1-fig4

$97 \times 242 \mathrm{~mm}(300 \times 300 \mathrm{DPI})$ 


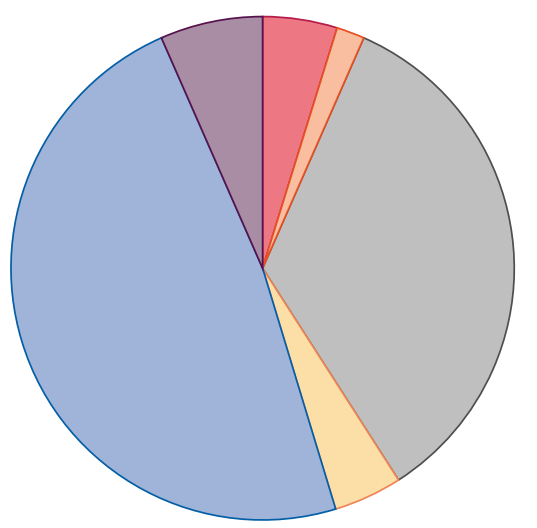

$\square$ Cardiology

$\square$ Hepatology

$\square$ Intensive care

Medical unit

$\square$ Nephrology

$\square$ Other 